anr symptom which indicated that any disease remained in the spine. The probability is, that the disease was entirely eradi. cated; that callus was formed to supply the loss of whatever bony matter had been removed, and all the consequences were pre. rfnted which must otherwise have ensued. I saw this young lady many times afterwards rhile sle continued in England, and, as long as I lad opportunities of seeing her, she continued in good health.

One circumstance in this case is worthy of observation. Mr. Heaviside made the issues by incision. General Dumourier chose to be present when they were made, and afterwards declared, both to Mr. Heariside and myself, that he suffered more mental anguish in witnessing this operation than he had suffered in all the engagements he bad wituessed put together. Human Iature is composed of strange materials. This wholesale destroyer of human life could cut down his thousand and ten thousand of buman beings, with no other feeling than that of a desire to cut down as many more; $y$ the trembled at the sight of an operation of no very terrific appearance, performed upon a young child, done to restore her to health, and perhaps to save her life.

This is one of the many cases which I could produce to show that the adoption of this practice, in the earliest stages of this disease, affords, what 1 may call, a certainty of stopping its progress. I see patients in every direction, who, in early life, were subjected to its ravages, and who, by adoptin the treatment I have described, were secured from its effects, and are now approaching old age. When a professional man is limself convinced of the propriety of following the course that has been described, the great difficulty he has to encounter is to persuade his patients, or their friends, to submit to the proper treatment in the early stages of the disease, at which time it may be used with the greatest advantage. A single point, formed by one spinal process, appears to project ontwards, either anong the dorsal or the lumbar vertebra; the child complains of pains in that part of the back which is near it, and perbaps of irregularity in the action of the legs. If a surgeon be consulted who understands the hats, and proposes the proper remedy, upon the ground that the existence of the disease is certain, and therefore the sooner the only effectual remedy is applied the better it will be for the patient; this, as Abernethy said upry another occasion, the parents will not blieve; they will not believe that a litlle Injection, such as that which they see, tan require such serious treatment; they mill consider about it, and consult their friends. Erery friend who is consulted has ome infallible remedy to propose, and nu- merous pretended remedies are brought into view. In a multitude of counsellors there is said to be wisdom, but in these cases there is nothing but folly. The stay-maker, the shape-mender, the spine-stretcher, are brought into play; and when, by their united exertions, the patient's disease and deformity are increased, the constitution is ruined, and life endangered. Recourse is again had to the surgeon, who is at last seriously consulted, and may think himself fortunate if even he saves that life with an injured constitution, which he might, with ease, have preserved in good health, if a rational system of treatment had been acted upon when he was first consulted. I saw many such cases during several years in which they were under the care of Mr. Ford. He always insisted, as soon as ho saw the decided projection of a single vertebra, not only upon forming issues to keep the discharge in the neighbourhood of the disease; but upon suspending the head as I have described, and upon kéeping the patient, as much as circumstances would permit, in the open air, with easy exercise, and attention to diet and medicine. He in. variably followed this course of treatment when he was allowed to act for himself, and when he did so, I never knew him lose a single patient. When they applied to him, after they had long persevered in a different course, and brought themselves into a dan. gerous situation, he, like others, had his imperfect cures and his total failures; but the uniformity of his success, when his patients from the beginning followed the course that he prescribed, indelibly fixed it upon my mind, that this is the course which, in the treatment of this class of spinal curvatures, ought to be followed to ensure suc. cess. I am, Sir, yours, \&c.

43, Allsop Terrace.

\section{'T. SHeLdrake.}

\section{NOTE FROM MR. SHELDRAKE.}

\section{To the Editor of The Lancet.}

SI,- I am not, in any manner, acquainted with your correspondent, Mr. J. H. Heaton, of Ticktill ; I will not, therefore, speak of him further than to say, that if I have written any thing that is unintelligible, incorrect, or untrue, that is a matter of fact which may be demonstrated; and if Mr. J. H. Heaton can, and will perform such demonstration, the profession and the public will be benefited, and I shall stand correct. ed and improved, for which I shall be very thankful. And am yours, \&c.

43, Allsop Terrace.
T. SHELDRAKE. 